\title{
Electrodeposition of copper applied to the manufacture of seamless superconducting rf cavities
}

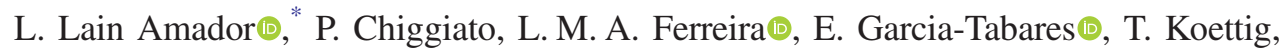 \\ M. S. Meyer, A. T. Perez-Fontenla๑, K. Puthran $\odot$, G. Rosaz@, and M. Taborelli® \\ CERN, 1211 Geneva 23, Switzerland
}

(Received 6 May 2021; accepted 26 July 2021; published 16 August 2021)

\begin{abstract}
Niobium thin film coated copper superconducting radio frequency elliptical cavities have demonstrated for many years their strong potential as an alternative to bulk niobium cavities. The thin film lower performance at high rf field is often attributed to the defects observed in the elaborated $\mathrm{Nb}$ layer, sometimes originated from defects inherited from the substrate itself. The currently used methods of manufacturing the copper elliptical substrates include several steps of electron-beam welding in order to join the half cells and the cutoffs which can contribute to defects and porosities. Seamless methods are nowadays developed in order to avoid welding steps and to decrease the global manufacturing cost of the cavities. We propose in this study an innovative alternative route in which the cavity is formed by electrodeposition of copper on a sacrificial aluminum mandrel. The strength of the process relies on the total absence of welding joints. Two different electroforming techniques using either direct current or pulsed plating have been investigated. The electroformed copper exhibited similar mechanical robustness, cryogenic properties and purity as the oxygen-free copper. In addition, the fabrication process was validated on test mandrels which mimic the geometry of $1.3 \mathrm{GHz}$ cavities.
\end{abstract}

DOI: $10.1103 /$ PhysRevAccelBeams.24.082002

\section{INTRODUCTION}

Radio frequency cavities are resonant devices used in particle accelerators to accelerate charged particle beams. Although cavities can be built of normal conducting materials, the use of superconducting ones increases the portion of the rf energy that accelerates the beam, reducing losses by heat dissipation on the cavity wall. Very good performance is obtained from massive niobium cavities which have a very low surface resistance [1]. However, the high cost of niobium triggered the research of less expensive and more efficient cavity fabrication methods as, for example, through the use of thin films [2,3]. At CERN, $\mathrm{Nb}$ coating on copper technology was developed and was successfully used for the production of cavities for the Large Electron Positron Collider (LEP) and was chosen again for the quarter wave resonators (QWR) fabrication of the HIE-ISOLDE beam facility [4]. The bottleneck of $\mathrm{Nb}$ thin films is the strong increase of surface resistance as a function of the rf field amplitude which makes the technology adapted only to low-accelerating gradient

\footnotetext{
*1ucia.lain.amador@cern.ch

Published by the American Physical Society under the terms of the Creative Commons Attribution 4.0 International license. Further distribution of this work must maintain attribution to the author(s) and the published article's title, journal citation, and DOI.
}

applications. Calatroni et al. [5,6] suggested that the film defects, which are sometimes observed in the deposited $\mathrm{Nb}$ layer, could explain the limits of the rf performance. Those are sometimes originated from defects inherited from the copper substrate itself. This was observed with the HIEISOLDE QWR coated cavities, where a systematic loss of performance observed on the electron-beam welded cavities revealed the importance of using seamless substrates [7]. Moreover, Palmieri et al. introduced a thermal boundary model which explained the decrease of $\mathrm{rf}$ performance based on the quality of the thermal contact at the $\mathrm{Nb} / \mathrm{Cu}$ interface [8].

Superconducting radio frequency (SRF) copper elliptical cavity substrates are normally manufactured via sheet metal working and welding. The process consists in the forming of the two separated half cells by using either a spinning or electro-hydroforming process. Both are then joined together and to the cutoffs by electron-beam welding (see Fig. 1 for nomenclature). In this approach, porosities can potentially form along the junction line. On top of that, the welding seams are localized in crucial regions such as the iris and equator, which are very critical for $\mathrm{rf}$ performance because they are respectively exposed to high electric and magnetic field [9].

Manufacturing of seamless cavities has been approached by different methods over the past decades [10]. Hydroforming was first explored at Cornell University [11] and at CERN [12]. Here the cavity is produced by 


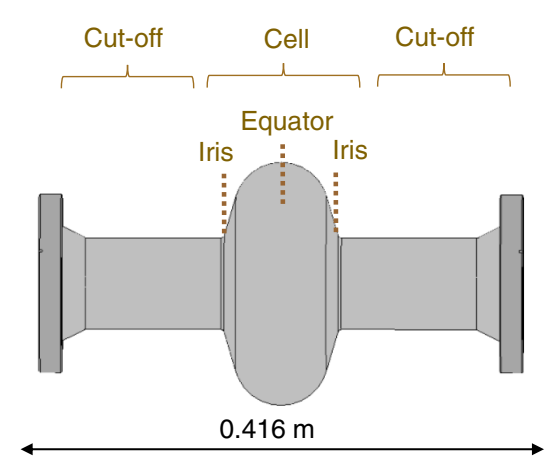

FIG. 1. 1.3 GHz TESLA-type elliptical SRF cavity dimensions and nomenclature.

bulge forming a tube that has been previously necked to maintain a more homogeneous thickness. The main limitation for such an approach is the need of multiple forming steps with intermediate annealings, which increases the complexity of the process [13,14]. Singer et al. [15] claimed that the performance of $\mathrm{Nb}$ seamless cavities produced at DESY by hydroforming was comparable to welded cavities. Another seamless process in which the cell is entirely spun around a mandrel and then electron-beam welded to the cutoffs is currently investigated at INFN [16]. This process has been already used to manufacture several $1.3 \mathrm{GHz}$ copper cavities. However, cracks are sometimes observed on the inner surface of the cavity, due to the high stress undergone in the process, and it requires the use of complex polishing techniques to remove the damaged surface leading to a difficult control of the final cavity's thickness. Moreover this spinning technique faces difficulties in achieving the required mechanical tolerance. An alternative seamless route is the use of galvanic processes [17]. Electrodeposition of copper on a metallized glass mandrel was successfully used to manufacture copper cavities at CERN in the 1990s [18]. These cavities did not achieve the expected mirrorlike surface from the glass die due to the chemical etching process of the die, which was only achieved with the use of highly corrosive and toxic hydrofluoric acid mixtures that also attacked the smooth copper inner surface and increased its roughness. Recent research on electroforming of small diameter vacuum chambers [19] put in evidence that aluminum mandrels have the advantage of a simpler etching strategy that does not jeopardize the copper inner surface state.

The aim of this research is to develop a seamless process in which a copper cavity is produced by copper electroplating on an aluminum sacrificial mandrel, which has the inner shape of the cavity, as seen in Fig. 2. The electroforming process joins the stainless steel vacuum flanges to the copper cavity, building full-seamless cavities. The inner surface state of the cavity is given by the surface finish of the aluminum mandrel, which implies that very smooth surfaces can be achieved when polished mandrels are used. After a description of the methods for the preparation of a

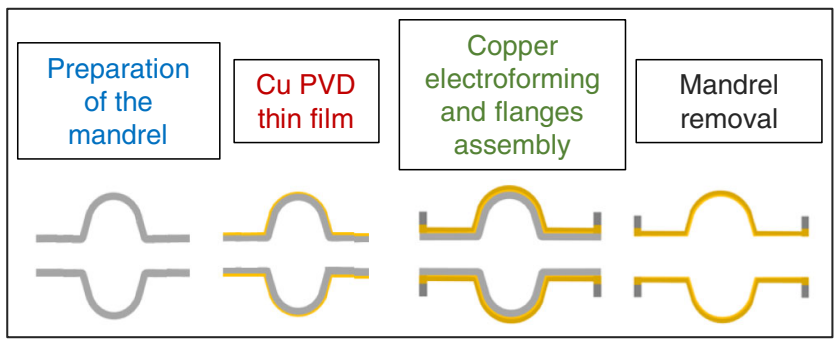

FIG. 2. The main steps of the production process: preparation of the mandrel, copper thin film coating by DC magnetron sputtering, the electroforming of the cavity, and the removal of the mandrel.

dummy cavity and witness samples, this article describes the mechanical and cryogenic properties of the electroformed copper and the experimental aided with simulation validation of the electroforming manufacturing process.

\section{EXPERIMENTAL PROCEDURE}

\section{A. Sample preparation}

Two different samples were produced for this research: flat disks and dummy mandrels that resembled the shape of $1.3 \mathrm{GHz}$ tesla-type elliptical cavities. Disk samples of $150 \mathrm{~mm}$ diameter were machined by milling from aluminum sheets of $1.5 \mathrm{~mm}$ thickness with two different surface finishes: standard machining with an average roughness on the surface of $0.49 \mu \mathrm{m}$ and diamond machining with a reduced roughness of $0.002 \mu \mathrm{m}$. The dummy mandrels were produced by Tungsten Inert Gas (TIG) welding together two aluminum vessels together and to two aluminum cutoff tubes of $2 \mathrm{~mm}$ thickness. The vessel heads were chosen to be as close as possible to $1.3 \mathrm{GHz}$ half cell dimensions. For both shapes, the mandrel was made of aluminum AW-6082 alloy. Afterward, a precursor copper layer was applied to increase adhesion of the subsequential electroformed layer. For such a purpose, copper thin film coating was performed via DC magnetron sputtering on the degreased mandrel (alkaline solution at $\left.60^{\circ} \mathrm{C}, 15 \mathrm{~min}\right)$. An oxygen-free copper disk cathode was used to sputter $3 \mu \mathrm{m}$ of $\mathrm{Cu}$ with an average power of $380 \mathrm{~W}$, using $\mathrm{Kr}$ as a sputtering process gas. In order to obtain a uniform coating on the surface of the mandrel, this was translated and rotated around its axis during the coating. On the other hand, the flat samples were supported by a fixed grid facing the cathode.

For the dummy mandrels, dedicated ConFlat flanges were designed and machined from 316LN stainless steel. On the cutoff side a conical lip at $26^{\circ}$ ensures a smooth transition from the flat plane of the flange to the cylindrical wall of the mandrel. The flanges were nickel and copper flash electroplated prior to electroforming. Afterward, flanges and mandrel were mechanically assembled together and the resulting assembly was prepared for copper plating. 
The flat disk samples were held on a specific support, which protected the rear side of the aluminum plate.

The samples were copper plated in an acidic copper sulfate bath $\left(\mathrm{Cu} 38 \mathrm{~g} / \mathrm{l}, \mathrm{H}_{2} \mathrm{SO}_{4} 100 \mathrm{ml} / \mathrm{l}\right)$ using two different plating procedures: pulse plating on the mentioned bath without additives or direct current plating adding a commercial complex brightener to increase smoothness. The applied average current density for both processes was $160 \mathrm{~A} \cdot \mathrm{m}^{-2}$. The pulse plating was performed in pulses of $7 \mathrm{~ms}$ on-time and $8 \mathrm{~ms}$ off-time.

Finally, the electroformed disk/assembly underwent chemical etching on $\mathrm{NaOH} 200 \mathrm{~g} / 1$ to remove the aluminum mandrel. After complete removal of the mandrel, acidic ammonium persulfate rinsing $(150 \mathrm{~g} / \mathrm{l})$ was performed to remove surface impurities, which were part of the aluminum alloy and are not removed by the $\mathrm{NaOH}$ solution [20]. At the end of the process, the samples were rinsed with deionized water followed with ethanol and finally dried. After this step, the copper coating was visible on the inner surface of the disk or test cavity.

\section{B. Sample characterization methods}

Standard tensile specimens and rectangular samples "L" $(20 \mathrm{~mm} \times 60 \mathrm{~mm})$, "M" $(10 \mathrm{~mm} \times 20 \mathrm{~mm})$ and "S" $(2 \mathrm{~mm} \times 110 \mathrm{~mm})$ were extracted from the $2 \mathrm{~mm}$ thick electroformed disks by electroerosion cutting. Mechanical tests were performed on the specimens with an ultimate tensile strength (UTS) electromechanical testing machine equipped with a $200 \mathrm{kN}$ load cell. The Young's modulus was calculated by the impulse excitation technique on the rectangular samples "L" following ASTM-E1876 [21]. The microstructure of the electroformed copper was observed on a LEICA Q600 optical microscope after the samples of dimension " $\mathrm{M}$ " were polished and chemically etched ( $5 \mathrm{~g}$ of $\mathrm{FeCl}_{3}, 50 \mathrm{ml}$ of $\mathrm{HCl}$ and $100 \mathrm{ml} \mathrm{of} \mathrm{H}_{2} \mathrm{O}$ ). The surface roughness was measured on the surface of samples "M" with a surface optical profiler VEECO-NT 3300.

The residual resistivity ratio (RRR) and thermal conductivity were measured on "S" samples, which were etched with ammonium persulfate (50 $\mu \mathrm{m}$ removal) and passivated in chromic acid to remove the oxide layer produced during the cutting [22].

RRR was determined by measuring the samples in a four-wire configuration with an electrical current of $5 \mathrm{~A}$. The respective voltage drop was determined at the sample length of $110 \mathrm{~mm}$. The samples themselves were thermalized on a $\mathrm{Cu}$ platform surrounded by a thermal shield all in insulation vacuum of $\mathrm{p}<10^{-6}$ mbar. The samples were conduction cooled via Kapton tape electrical insulators with the cooling provided by a helium phase separator, which was kept at $4.2 \mathrm{~K}$ helium saturation conditions. The cryostat setup allowed the measurement of the electrical resistance of the samples at room temperature and at $4.2 \mathrm{~K}$ without altering the four-wire electrical contacts on the samples. Given the fact that the thermal screen minimized heat loads to the sample environment and all incoming cabling was thermally anchored at the thermal screen and the phase separator stages, the estimated measurement error for the sample temperature was $\mathrm{dT}_{4.2 \mathrm{~K}}= \pm 0.08 \mathrm{~K}$ and the $\mathrm{dT}_{293 \mathrm{~K}} \pm 0.6 \mathrm{~K}$. The relative accuracy of the RRR value was then estimated to be $\Delta \mathrm{RRR} / \mathrm{RRR}= \pm 5 \%$.

Thermal conductivity measurements were performed using a steady-state method [23] in the temperature range between 3.5 and $40 \mathrm{~K}$. An electric heater, mounted on the free end of the sample, generated a heating power, $\dot{Q}$ that in turn caused a temperature gradient $\Delta \mathrm{T}$ along the active length $L$ of the sample; this $\Delta \mathrm{T}$ was measured as the recorded temperature difference between two temperature sensors mounted on the sample separated by characteristic or active length $L$. The thermal conductivity $\lambda$ was obtained from Fourier's law of heat conduction between the applied heat flux and recorded temperature difference [Eq. (1)]:

$$
\lambda=\frac{\dot{Q} L}{A \Delta T},
$$

where A is the cross-section area of the sample. The experimental platform was thermally linked to the second stage of a pulse tube cryocooler via a copper rod. It reached $2.9 \mathrm{~K}$ at no load and could provide up to $1 \mathrm{~W}$ cooling power at $4.2 \mathrm{~K}$. Insulation vacuum in the order of $10^{-5}$ mbar was reached before the system is cooled down. The measurement error calculation considered the precision of the current sources, temperature measurements and uncertainties in sample dimensions. The absolute error for temperature measurement in the low temperature range $(4.5 \mathrm{~K})$ was $\Delta \mathrm{T}= \pm 8 \mathrm{mK}$, whereas in the high temperature range (40 K) was $\Delta \mathrm{T}= \pm 75 \mathrm{mK}$. The relative error for the thermal conductivity data was $\pm 1 \%$.

Copper impurity content of " $\mathrm{L}$ " samples was measured by glow discharge mass spectrometry (GDMS) and interstitial gas analysis (IGA) in EAG laboratories (Tournefeuille, France). For the electroformed dummy cavities, the thickness of the electroplated layer was measured with an Olympus Magma-Mike 8600 thickness gauge.

\section{Simulation methods}

The electroforming process was modeled with COMSOL Multiphysics using the electrodeposition primary and secondary current distribution physics module. The boundary displacements resulting from the plated thickness at the cathode and the anodic dissolution were included in the simulation thanks to a moving mesh. The electron transfer reactions that take place on the anode and the cathode are the following, assuming a 100\% yield:

$$
\begin{array}{r}
\text { Anode: } \mathrm{Cu}_{(\mathrm{s})} \rightarrow \mathrm{Cu}^{2+}+2 \mathrm{e}^{-} \\
\text {Cathode: } \mathrm{Cu}^{2+}+2 \mathrm{e}^{-} \rightarrow \mathrm{Cu}_{(\mathrm{s})} .
\end{array}
$$


The relationship between the local current density $\left(i_{l}\right)$, at any point in the electroforming bath, and the local potential derivative $\left(\phi_{l}\right)$ is described by Ohm's law:

$$
\begin{aligned}
i_{1} & =-\sigma \nabla \phi_{1}, \\
\nabla \cdot i_{1} & =0,
\end{aligned}
$$

where $\sigma$ is the conductivity of the electrolyte. In the absence of concentration gradients and reaction kinetics, the current distribution is called primary current distribution (PCD) and it only depends on the electrolyte's Ohmic resistance and the geometry of the electrolytic bath. For its assessment, the following boundary conditions along the cathode, anode and insulating walls are applied where $\xi$ is the unit vector normal to the electrode surface, $s$ is the surface of the cathode and $i_{\text {avg }}$ is the average current density:

$$
\begin{array}{rlrl}
\int\left(\xi \cdot i_{1}\right) d s & =i_{\text {avg }} \int d s, \quad \text { on the cathode, } \\
\phi_{1} & =0 \quad & & \text { on the anode, } \\
\xi \cdot i_{1} & =0 & & \text { along the insulating walls. }
\end{array}
$$

The secondary current distribution (SCD) also neglects the influence of concentration variations in the electrolyte but accounts for the reaction kinetics. The kinetics is defined by the activation overpotential $\left(\eta_{C u}\right)$ of the reaction at the electrode/electrolyte interface. The activation overpotential is the difference between the actual potential difference and the equilibrium potential $\left(E_{\text {eq, } \mathrm{Cu}}\right)$ :

$$
\eta_{\mathrm{Cu}}=\phi_{\mathrm{s}}-\phi_{1}-E_{\mathrm{eq}, \mathrm{Cu}} .
$$

A kinetic relation links the electrode overpotential to the local current density. The local current density equation at the electrode surface is described by the Butler-Volmer equation [24]:

$i_{\mathrm{loc}, \mathrm{Cu}}=i_{0, \mathrm{Cu}}\left[\exp \left(\frac{\alpha_{\mathrm{a}} \cdot F \cdot \eta_{\mathrm{Cu}}}{R \cdot T}\right)-\exp \left(\frac{-\alpha_{\mathrm{c}} \cdot F \cdot \eta_{\mathrm{Cu}}}{R \cdot T}\right)\right]$,

where $i_{\mathrm{loc}, \mathrm{Cu}}$ is the local current density, $i_{0, \mathrm{Cu}}$ is the exchange current density, and $\alpha_{c}$ and $\alpha_{a}$ are the transfer coefficients for the cathodic and anodic reaction, respectively. In the case of a symmetric reaction, the sum of both is equal to unity.

The kinetic parameters and electrolyte properties are given in Table I. The rate of deposition at the cathode boundary surface and the rate of dissolution at the anode boundary surface are calculated according to Eq. (7), which is derived from the Faraday's law where $M$ is the molar mass of the deposited metal $(63.35 \mathrm{~g} / \mathrm{mol}), \rho$ is the density $\left(8.96 \mathrm{~g} / \mathrm{cm}^{3}\right), F$ is the Faraday constant $\left(96485 \mathrm{C} \mathrm{mol}^{-1}\right)$
TABLE I. Kinetics parameters and electrolyte properties.

\begin{tabular}{lcc}
\hline \hline Parameter & Value & Unit \\
\hline$i_{0, \mathrm{Cu}}$ & 0.1 & $\mathrm{~A} \cdot \mathrm{m}^{-2}$ \\
$\alpha_{\mathrm{c}}, \alpha_{\mathrm{a}}$ & 0.5 & $\cdots$ \\
$E_{\mathrm{eq}, \mathrm{Cu}}$ & 0.33 & $\mathrm{~V}$ \\
$\mathrm{CuSO}_{4}$ & 0.5 & $\mathrm{M}$ \\
Conductivity & 15 & $\mathrm{~S} / \mathrm{m}$ \\
\hline \hline
\end{tabular}

and $n$ is the number of electrons exchanged in the reaction (two electrons):

$$
v=\frac{i_{\mathrm{loc}, \mathrm{Cu}}}{n \cdot F} \cdot \frac{M}{\rho}
$$

\section{RESULTS}

\section{A. Electroformed copper mechanical properties}

Tensile testing was performed on the electroformed copper specimens and on reference copper oxygen-free electronic (OFE) specimens, which were prepared from cold-rolled copper sheets procured at CERN from the same quality as the ones used for the preparation of the $400 \mathrm{MHz}$ LHC cavities. The results of the tensile tests are shown in Fig. 3 and the characteristics calculated in Table II with the addition of the elastic modulus results from the excitation test.

The electroformed copper specimens produced with DC plating in the presence of brightener exhibit a higher ultimate tensile strength and yield strength (YS) than reference cold-rolled OFE copper. The electroformed specimens produced by pulse current in the bath without additives exhibit worse mechanical properties than the other cases. The yield strength and ultimate tensile strength are lower when compared to cold-rolled copper OFE but are still within the acceptable margin for the exploitation of

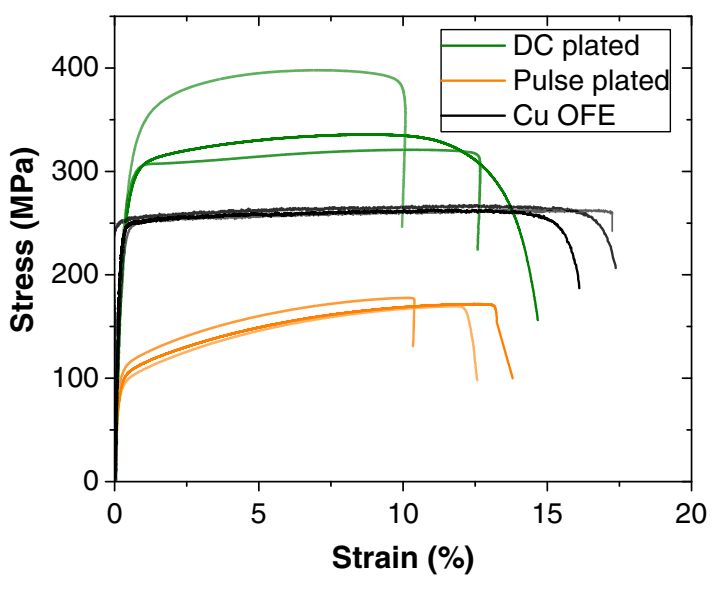

FIG. 3. Stress vs strain curves for the different copper analyzed: $\mathrm{Cu}$ OFE in black, $\mathrm{Cu}$ DC plated in green and $\mathrm{Cu}$ pulse plated in orange. 
TABLE II. Ultimate tensile strength, yield strength (YS) and elongation values measured via tensile testing ( 3 specimens per case). Elastic modulus is measured with the impact excitation technique.

\begin{tabular}{lcccc}
\hline \hline $\begin{array}{l}\text { Specimen } \\
\text { sample }\end{array}$ & UTS (MPa) & YS (MPa) & Elongation (\%) & E (GPa) \\
\hline Cu OFE & $263 \pm 0$ & $243 \pm 6$ & $16 \pm 1$ & $125 \pm 10$ \\
DC plated & $328 \pm 22$ & $268 \pm 16$ & $14 \pm 3$ & $124 \pm 14$ \\
Pulse plated & $170 \pm 15$ & $106 \pm 10$ & $13 \pm 2$ & $131 \pm 15$ \\
\hline \hline
\end{tabular}

this electroforming process [20]. We remark that for the LHC $400 \mathrm{MHz}$ cavities the weakest region from the mechanical point of view is the electron beam weld. It has been measured to be at $30 \mathrm{MPa}$ YS and $190 \mathrm{MPa}$ UTS and the corresponding cavities were successfully tested for rf performance. The elongation at break of both electroformed copper is slightly lower than the one for cold-rolled OFE copper. In addition, the Young's modulus of both electroformed samples is comparable with the reference OFE value of about $125 \pm 10 \mathrm{GPa}$.

The differences in grain structure between the two types of electroforming are shown in Fig. 4. DC plated samples exhibit a fine-grained structure with an average grain diameter of $2 \pm 1 \mu \mathrm{m}$, while the pulse plated samples show

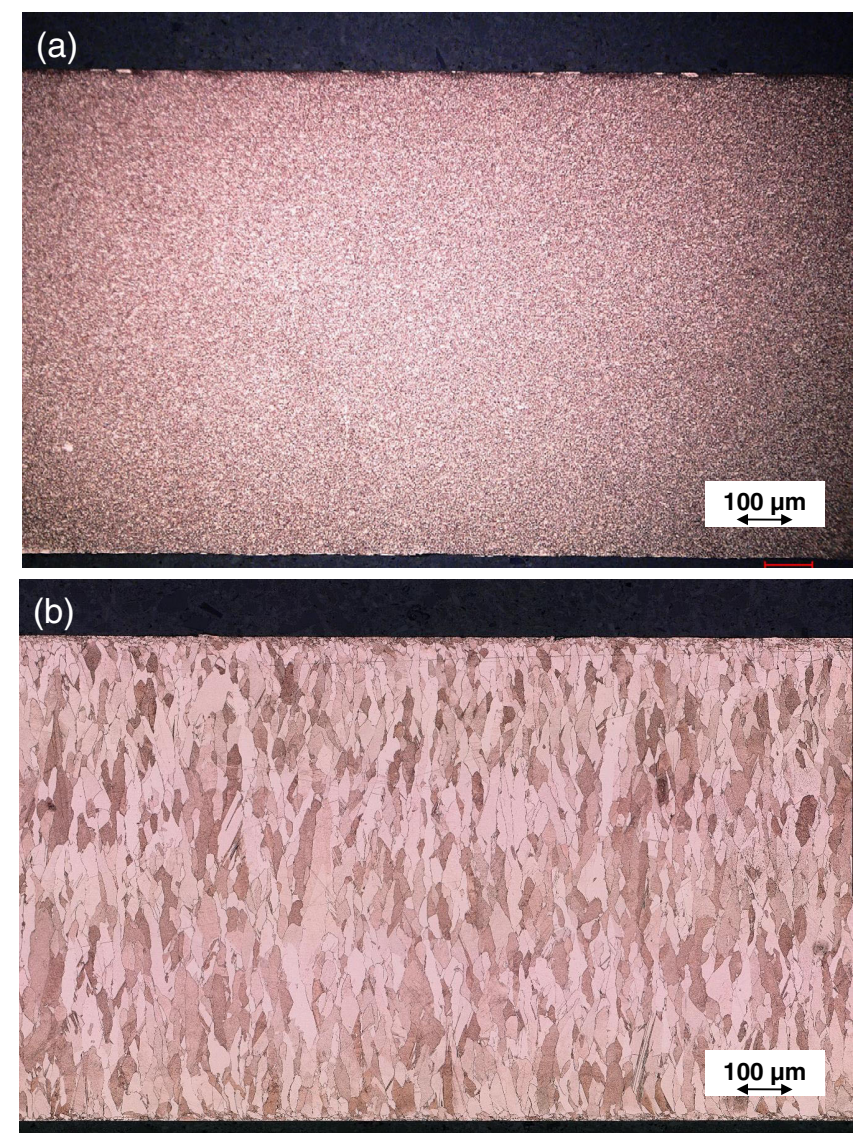

FIG. 4. Optical microscope images of copper samples after microetching: (a) DC plated copper, (b) pulse plated copper. columnar growth normal to the surface with an average grain size of $30 \mu \mathrm{m}$, measured following ASTM-E112 [25] in the horizontal plane. In addition, the pulse plated grains are not equiaxial, and the grain column length was estimated to be between 30 and $100 \mu \mathrm{m}$. The average grain size for the reference OFE copper is $12 \pm 2 \mu \mathrm{m}$.

The grain size values explain the measured mechanical parameters via the Hall-Petch relation [26]. This relation indicates that the yield stress of a material is equal to the sum of frictional stress (constant) and the inverse of the square root of the grain size. Fine grained deposits (DC plating) exhibited better mechanical performance than OFE copper. On the contrary, the large columnar grains explain the poorer mechanical behavior for the pulse plated samples. An intermediate phenomenon occurs in the case of fibrous deposits, not explored in this research, when stress relieving additives (such as gelatin, phenosulfonic acid or coumarin) are added to the copper sulfate bath [27].

The copper surface roughness on the side in contact with the aluminum, which corresponds to the copper inner surface of the cavity, was measured for different samples after mandrel removal. There were two different surface finishing processes on the mandrel: standard and diamond machining. The results (Table III) show that the roughness of the copper inner layer is influenced by the aluminum mandrel roughness and decreased 1 order of magnitude from 0.5 to $0.02 \mu \mathrm{m}$ by applying diamond machining finishing on the mandrel. Moreover, both electroforming procedures achieve comparable surface roughness, which is expected since the plating layer builds up on top of the coated layer that defines the roughness.

\section{B. Cryogenic properties}

For a good performance of the superconducting cavity, a high thermal conductivity in the cavity wall is required. The thermal conductivity can be indirectly measured by its relation to the residual resistivity ratio [28]. Most laboratories and companies working with SRF cavities prefer to use the RRR as the first criterion of the level of purity, as it can be measured more easily and quickly compared to thermal conductivity [29].

$\mathrm{RRR}$ [referred to as $\beta$ in Eq. (8)] is calculated as the ratio of the resistance at room temperature and the resistance at liquid helium temperature $(4.2 \mathrm{~K})$ :

TABLE III. Roughness ( $\mu \mathrm{m})$ of aluminum mandrel and copper inner surface for different mandrel surface finishing process. Direct plated (DC) samples are compared to pulse plated (PP) samples.

\begin{tabular}{lccccc}
\hline \hline $\mathrm{Ra} \mu \mathrm{m}$ & \multicolumn{2}{c}{ Standard machining } & & \multicolumn{2}{c}{ Diamond machining } \\
\cline { 2 - 3 } \cline { 5 - 6 } $\mathrm{Ra} \mathrm{Al}$ & \multicolumn{2}{c}{$0.49 \pm 0.05$} & & \multicolumn{2}{c}{$0.002 \pm 0.001$} \\
\hline Samples & $\mathrm{DC}$ & $\mathrm{PP}$ & & $\mathrm{DC}$ & $\mathrm{PP}$ \\
$\mathrm{Ra} \mathrm{Cu}$ & $0.39 \pm 0.04$ & $0.65 \pm 0.01$ & & $0.023 \pm 0$ & $0.028 \pm 0$ \\
\hline \hline
\end{tabular}




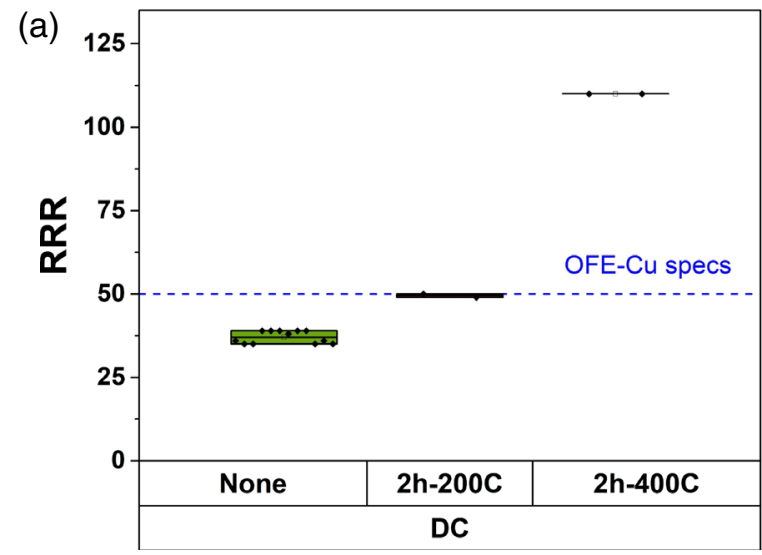

(b)

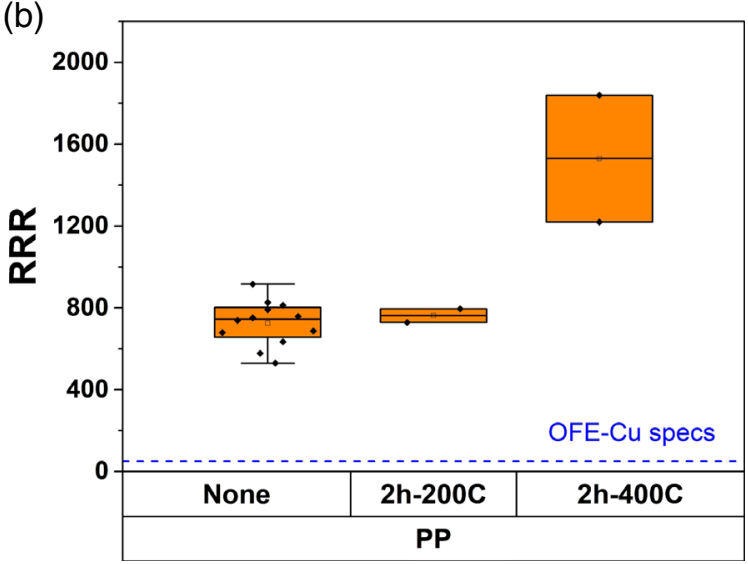

FIG. 5. Residual resistivity ratio (RRR) values for (a) DC plated copper and (b) pulse plated copper at room temperature and after several annealing steps. $\mathrm{Cu}$ OFE specification is added as a reference from [30].

$$
\beta=\frac{R_{298}}{R_{4.2}} .
$$

The RRR results for the electroformed copper are shown in Fig. 5 and are compared to the copper OFE specification $(\mathrm{RRR}=50)$ [30]. The DC electroformed copper for asdeposited layers exhibits a lower RRR than the copper OFE specification. Several heating steps improved the ratio up to 115 after $400{ }^{\circ} \mathrm{C}$ treatment for 2 hours. In the case of pulse plated copper, the RRR value exceeds the specification with an average around 700 for as-deposited layers, which is improved to 1600 after thermal annealing at $400{ }^{\circ} \mathrm{C}$ for 2 hours. For both electroformed copper, the RRR increased after annealing which favors the removal of interstitial impurities in the material. In the work of Kim et al. [31] and Fickett [32], the RRR of OFE copper also increases with heat treatment upon a maximum of 300 at $500^{\circ} \mathrm{C}$.

Due to the very high RRR values reported. which are close to the sensitivity limit of our four-probes system, we decided to perform thermal conductivity measurements in order to cross-check the values. In Fig. 6, the thermal conductivity value for the two electroformed copper methods is assessed and compared with theoretical values

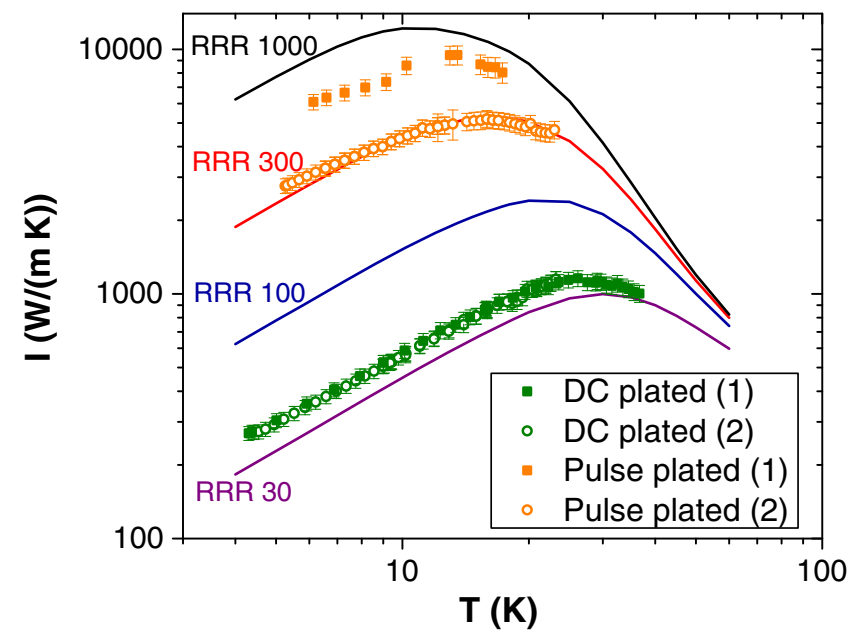

FIG. 6. Dependence of $\mathrm{Cu}$ thermal conductivity on temperature for different RRR extracted from Ref. [33]. Experimental values for the DC plated (green) and pulse plated samples (orange) are added to the plot.

of conductivity for different RRR values [33]. The samples were measured just after deposition without thermal treatment. The values are in agreement with the previous measured RRR, with higher values (RRR of 300-800) for pulse plated copper and lower values (RRR of 40) for the DC electroformed copper. The value expected for OFE copper at $4.2 \mathrm{~K}$ is $400 \mathrm{~W} \mathrm{~m}^{-1} \mathrm{~K}^{-1}(\mathrm{RRR}=50)$, which is slightly higher than the value measured for the DC plated copper. Pulse plated copper improves the thermal conductivity by a factor of 5 .

The differences in thermal conductivity and RRR can be explained by the level of impurities and lattice defects in the material $[29,34]$. The copper purity was qualified by means of IGA and GDMS and compared with reference values of copper OFE [30]. The results are shown in Table IV. The differences on impurity-level between the DC plated

TABLE IV. Chemical composition of electroformed copper compared to OFE copper (* indicates maximum values accepted extracted from the standard OFE specification [30]).

\begin{tabular}{lcccc}
\hline \hline $\begin{array}{l}\text { Impurity } \\
\text { (ppm wt.) }\end{array}$ & Cu OFE* & DC plated & $\begin{array}{c}\text { Pulse } \\
\text { plated }\end{array}$ & $\begin{array}{c}\text { Lab } \\
\text { technique }\end{array}$ \\
\hline $\mathrm{Ag}$ & 25 & 3.2 & 0.1 & GDMS \\
$\mathrm{As}$ & 5 & 0 & 0 & GDMS \\
$\mathrm{Cl}$ & $\ldots$ & 10 & 2.3 & GDMS \\
$\mathrm{Fe}$ & 10 & 0 & 0 & GDMS \\
$\mathrm{Pb}$ & 5 & 0 & 0 & GDMS \\
$\mathrm{S}$ & 15 & 16 & 0.2 & GDMS \\
$\mathrm{Ni}$ & 10 & 0 & 0 & GDMS \\
$\mathrm{Te}$ & 2 & 0 & 0 & GDMS \\
$\mathrm{C}$ & 1 & 11 & 2 & IGA \\
$\mathrm{O}$ & 5 & 6.2 & 2.8 & IGA \\
$\mathrm{H}$ & $\cdots$ & 0.4 & 0.1 & IGA \\
\hline \hline
\end{tabular}


and pulse plated copper are evidenced. Pulse plated copper contains very low amount of impurities. Liu et al. [35] reported that the use of a complex brightener during deposition is known to incorporate impurities into the deposit. This is in agreement with the presence of higher quantities of $\mathrm{Cl}, \mathrm{S}, \mathrm{C}, \mathrm{H}$ and $\mathrm{O}$ on the $\mathrm{DC}$ plated copper. The oxygen content on this copper is higher than the OFE-Cu specification limit of $5 \mathrm{ppm}$ and explains the poorer RRR value. Previous studies [20] found that $\mathrm{H}_{2}$, oxygen and $\mathrm{CO}_{2}$ are released from the DC plated copper during heating in vacuum. This agrees with the RRR increase with annealing temperature shown in Fig. 5. However, the increment remains below what is reported by Kim et al. [31] on OFE copper (RRR of 250 after $400^{\circ} \mathrm{C}$ heat treatment) because other impurities like $\mathrm{Cl}$ and $\mathrm{S}$ are still strongly bonded to the copper lattice [36]. The DC plated samples were subjected again to GDMS analysis after $400{ }^{\circ} \mathrm{C}$ annealing treatment and the quantities of $\mathrm{Cl}$ and $\mathrm{S}$ remained similar (9 and $14 \mathrm{ppm}$ wt. respectively) to those measured after deposition (Table IV). The pulse plated copper exhibits purer composition than the OFE copper, with a lower content of $\mathrm{Ag}, \mathrm{S}$ and $\mathrm{O}$. This could explain the high RRR values obtained and is an indication of the good quality of this copper for rf application.

The DC plated substrate might eventually be annealed to $400{ }^{\circ} \mathrm{C}$ to increase the RRR. The mechanical properties of the annealed electroformed copper were not assessed yet with standard tensile testing, but were studied by means of Vickers microhardness HV 0.1 (Table V). The microhardness of the DC plated copper decreased from $117 \pm 3$ to $80 \pm 1$ ( $\mathrm{HV} 0.1,10 \mathrm{~s}$ ) after $400^{\circ} \mathrm{C}$ ( 2 hours) heat treatment, showing a similar trend as OFE copper, where a decrease from $83 \pm 2$ to $52 \pm 1$ ( $\mathrm{HV} \mathrm{0.1,10} \mathrm{s)} \mathrm{is} \mathrm{observed.}$ The hardness values for the DC plated copper after $400{ }^{\circ} \mathrm{C}$ annealing are similar to those for OFE at room temperature. Therefore for the DC plated copper, the mechanical properties are expected to decrease and still remain strong. In addition the pulse plated copper, already exhibiting coarse grains after deposition, only suffers a slight decrease in hardness after annealing. The results after $400^{\circ} \mathrm{C}$ annealing are very similar to those measured on the annealed OFE copper. In addition, the average grain area was analyzed by electron backscatter diffraction (EBSD) after polishing the copper samples. The grain area is preferred to the grain diameter due to the nonequiaxial grains which are present on the pulse plated copper. The results, Table VI, show grain growth as a consequence of

TABLE V. Vickers microhardness values (HV 0.1) before and after thermal treatment.

\begin{tabular}{lccc}
\hline \hline Vickers microhardness & DC plated & Pulse plated & Cu OFE \\
\hline None, RT & $117 \pm 3$ & $62 \pm 2$ & $83 \pm 2$ \\
$200^{\circ} \mathrm{C}, 2$ hours & $101 \pm 6$ & $60 \pm 5$ & Not measured \\
$400^{\circ} \mathrm{C}, 2$ hours & $83 \pm 1$ & $54 \pm 2$ & $52 \pm 1$ \\
\hline \hline
\end{tabular}

TABLE VI. EBSD average grain area analysis before and after thermal treatment.

\begin{tabular}{lcc}
\hline \hline Average grain area $\mu \mathrm{m}^{2}$ & DC plated & Pulse plated \\
\hline None, RT & 0.893 & 1163 \\
$200^{\circ} \mathrm{C}, 2$ hours & 0.934 & 1251 \\
$400^{\circ} \mathrm{C}, 2$ hours & 4.92 & 1320 \\
\hline \hline
\end{tabular}

recrystallization for the DC plated copper ( 5 times more grain area) after $400{ }^{\circ} \mathrm{C}, 2$ hours heat treatment. For the pulse plated copper, the grain growth is minimal. This trend is in agreement with the measured change in microhardness (Table V).

\section{Cavity electroforming assessment}

To validate the feasibility of manufacturing a cavity by electroforming, test mandrels with a similar geometry of a $1.3 \mathrm{GHz}$ cavity followed the preparation steps described in Sec. II A.

Figure 7 shows the electroformed test cavities after mandrel removal for the two processes: DC plating and pulse plating for a nominal plated thickness of $2 \mathrm{~mm}$. The stainless steel flanges were joined to the cavity during the electroforming step. Both cavities are vacuum tight which confirms the success of the chosen joining technique between the flanges and the cavity. The thickness of the electroformed layer along the cavity was measured with a thickness gauge. The ratio of thickness uniformity (measured over nominal) is calculated in Eq. (9) and the results are shown in Fig. 8:

$$
\text { thickness ratio }=\frac{\text { measured thickness }}{\text { nominal thickness }} .
$$
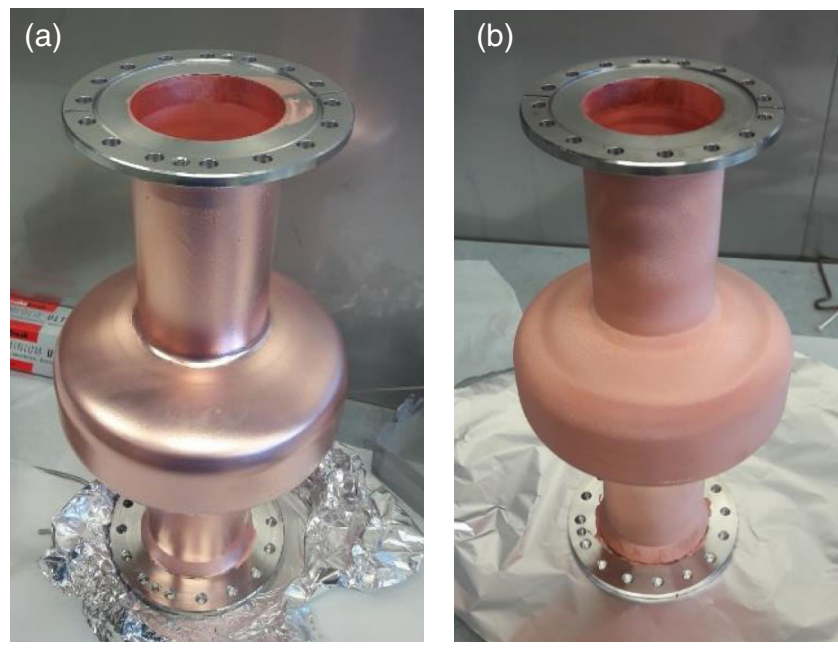

FIG. 7. Copper electroformed test cavities after mandrel removal for (a) direct plating in the bath with the brightener or (b) pulse plating. The stainless steel flanges are assembled during electrodeposition. 


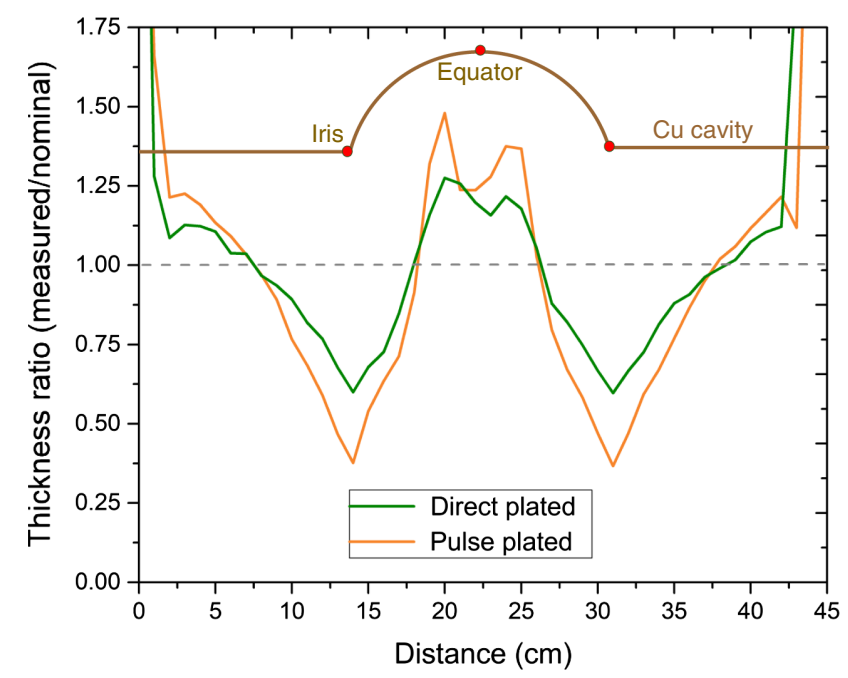

FIG. 8. Thickness ratio profile [Eq. (9)] along the length of the plated cavity. Direct plated values are represented in green and pulse plated ones in orange. The brown line is a simplified representation of the cavity geometry.

The thickness distribution is not uniform with a maximum at the equator of the cavity and a minimum at the iris. The difference on thickness uniformity between the two electroforming procedures is also shown. The brightener includes a leveler which evens the deposition rate across the cavity surface.

The cavities must be vacuum tight and robust in order to withstand the process steps of high pressure water rinsing, $\mathrm{Nb}$ coating, rf testing and later withstand atmospheric pressure when evacuated and put in operation. Therefore the cavities minimum thickness specification is defined to be $2 \mathrm{~mm}$. For the plated nominal thickness of $2 \mathrm{~mm}$, the thickness at the iris, which is the most critical part of the cavity subjected to buckling, is 1.2 and only $0.73 \mathrm{~mm}$ for DC and pulse plating, respectively. For both methods, DC and pulsed, the plating thickness remains below the nominal value in the most difficult region for electroplating, namely the cavity iris. For this reason, simulations of the electroplating process were performed, in order to predict the distribution of the current lines and the plating time to achieve the desired thickness at the iris.

\section{Simulations of the electroforming process}

The electrodeposition bath, cathode (cavity) and anodes were modeled in 3D by COMSOL as seen in Fig. 9. Time dependent simulations were run with the two electrode kinetics approaches from Sec. II C: primary and secondary current distribution. Both were used to measure the thickness distribution on the cavity after 76 hours at $1.6 \mathrm{~A} \cdot \mathrm{m}^{-2}$ as seen in Fig. 10. Both methods can be compared to experimental results obtained from the pulse plated cavities (single line). The primary current distribution approach (blue dots) fails to reproduce the behavior of the electrolyte
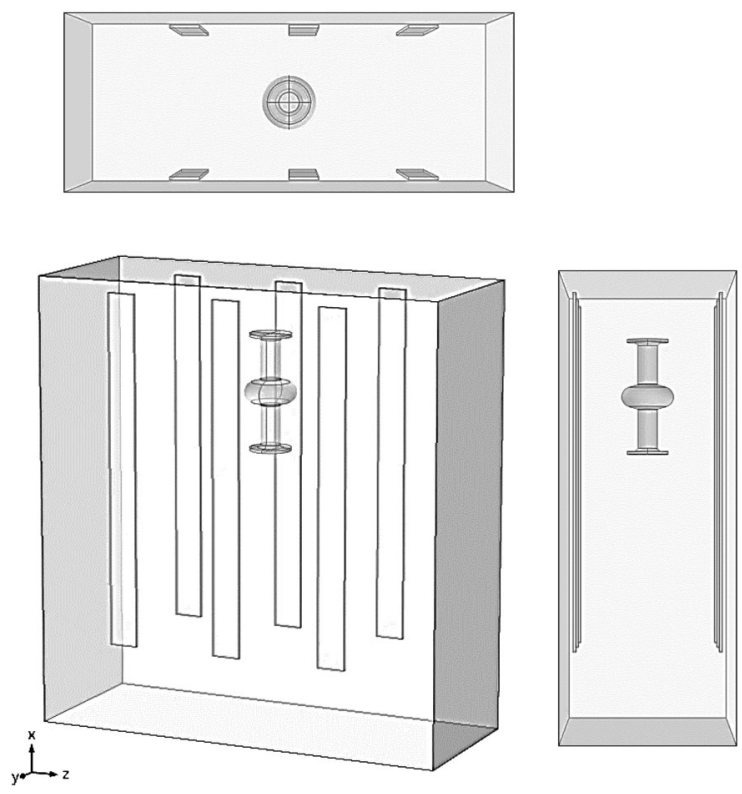

FIG. 9. 3D model of the electroforming process installation as it is shown in COMSOL.

at low current density areas. The secondary current distribution (orange dots) describes well the thickness distribution on the cavity. This is explained by the fact that the secondary distribution includes already the primary distribution and accounts in addition for activation overpotentials that induce a smoothing effect on the distribution of the current lines. Thus, the second current distribution approach was selected for all simulations.

Simulations successfully run for the copper sulfate electrolyte, but they fail to account the effect of the brightener in the solution. High throwing power electrolytes can be simulated by increasing the conductivity of the

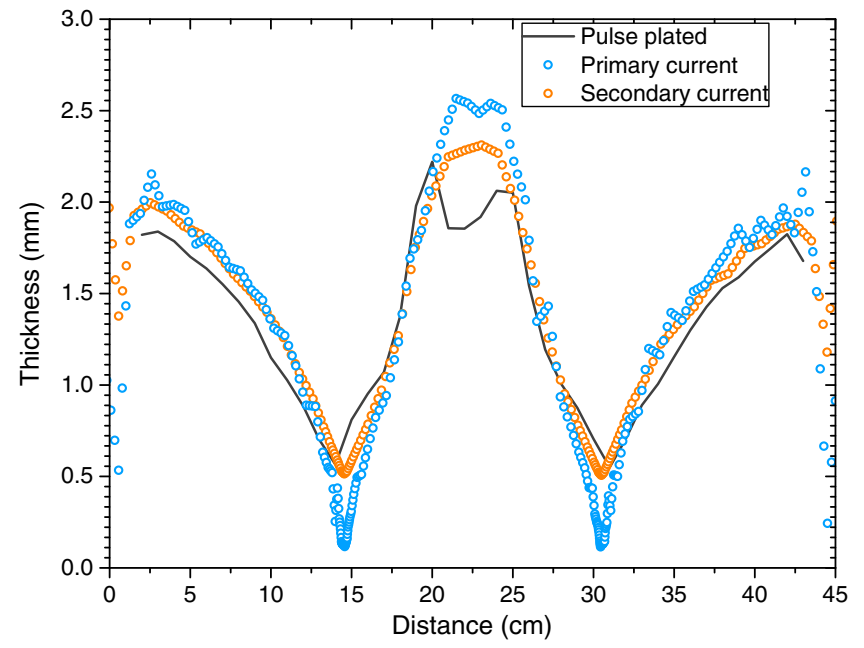

FIG. 10. Simulated thickness distribution after 76 hours at $160 \mathrm{~A} \cdot \mathrm{m}^{-2}$ for the two different electrode kinetics: PCD and SCD following Butler-Volmer. The experimental results from a pulse plated dummy are added in a single black line. 

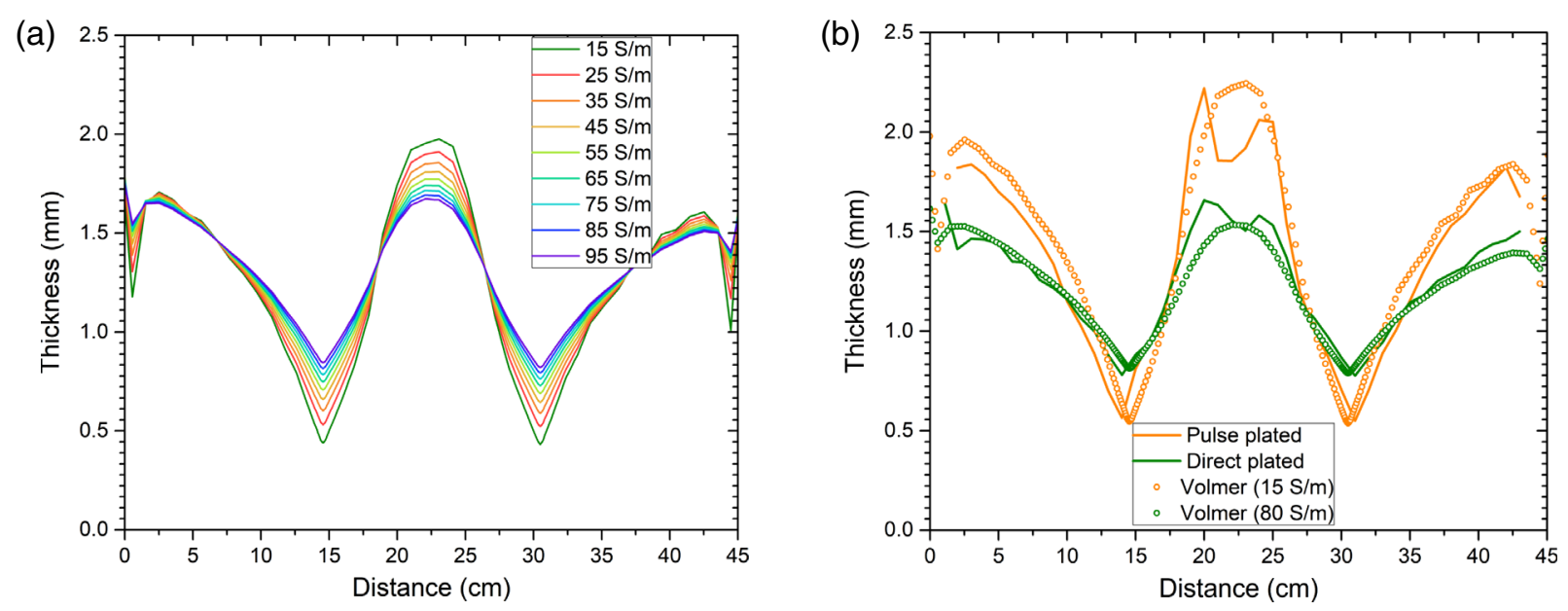

FIG. 11. (a) COMSOL simulated thickness distribution along the cavity for different electrolyte conductivity values after 65 hours plating at $160 \mathrm{~A} \cdot \mathrm{m}^{-2}$. (b) Comparison between the experimental thickness profile and the simulated one for the different electrolyte conductivities and different plating time.
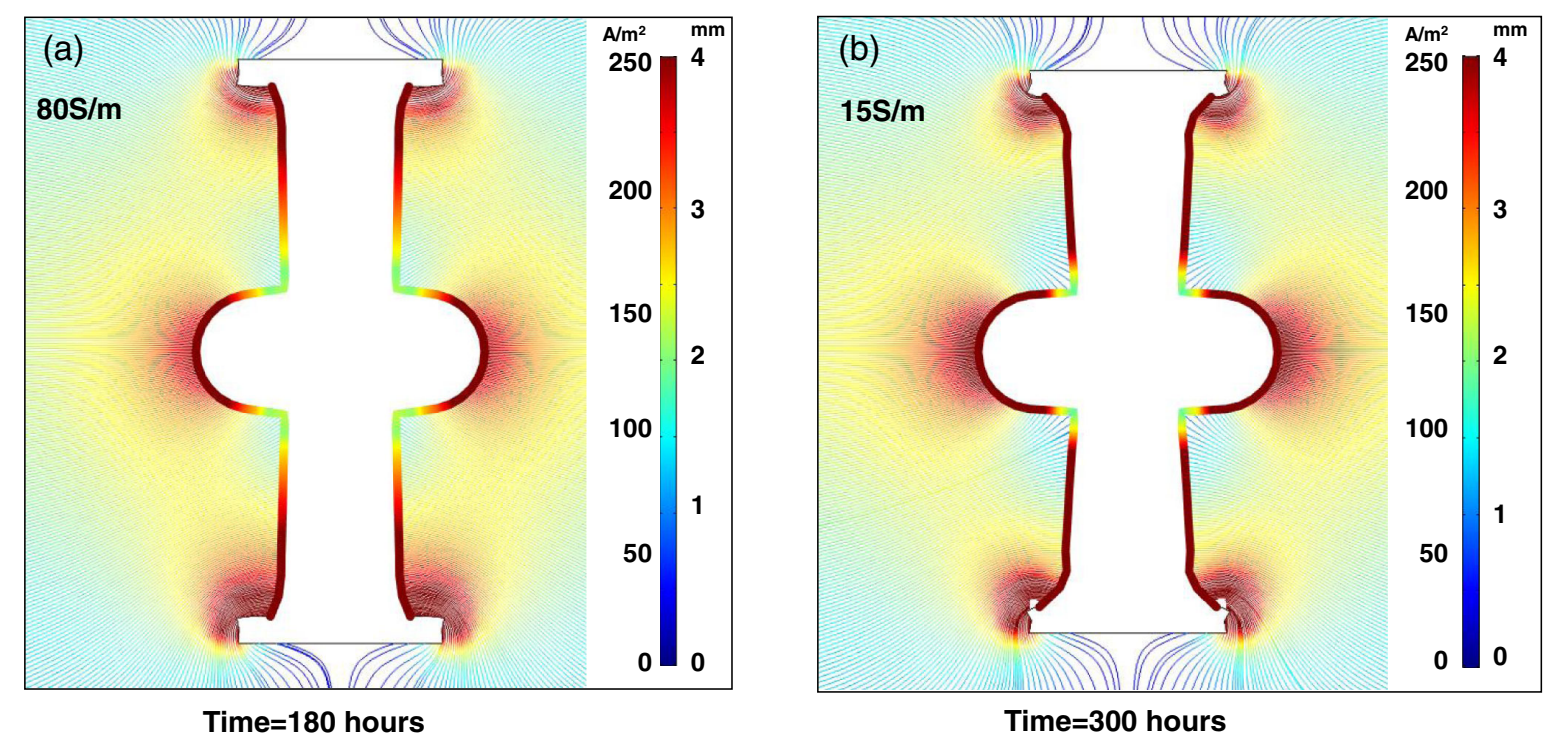

FIG. 12. COMSOL simulated deposited thickness $(\mathrm{mm})$ along the cavity and electrolyte current lines distribution $\left(\mathrm{A} \cdot \mathrm{m}^{-2}\right)$. (a) Solution from the bath with the brightener after 180 hours. (b) Solution from the bath without additives after 300 hours. In both cases the average current density is $160 \mathrm{~A} \cdot \mathrm{m}^{-2}$.

bath. This effect can be observed in Fig. 11(a). Although in reality the brightener does not alter the electrolyte conductivity, which remains around $15 \mathrm{~S} / \mathrm{m}$, the increase in throwing power is assumed to act similarly. Thus, the artificial increase in conductivity which mimics the observed increase in throwing power of the brightener is investigated and compared with experimental values. Several simulations confirmed that a conductivity of $80 \mathrm{~S} / \mathrm{m}$ increases the throwing power, in similar fashion as the additive. In Fig. 11(b), the experimental values from the dummy cavities (Fig. 8) are then compared with the simulated ones (for each electrolyte) with an average difference of around $8 \%$.
After the successful validation of the model, simulations were used to calculate the electroplating time to obtain a minimum thickness of $2 \mathrm{~mm}$ in the iris of the cavity, for each bath. In this case, the model was simplified to a 2D geometry, which is valid for cylindrical symmetry geometries. The current density and thickness profile of the cavity were obtained as seen in Fig. 12. On the figure, the geometry of the plated cavity represents the final shape of the object. On (a), the bath conductivity is set to $80(\mathrm{~S} / \mathrm{m})$ to simulate the bath with the brightener and on (b) to $15(\mathrm{~S} / \mathrm{m})$ to simulate the bath without additives. The minimum time, which provides a thickness of $2 \mathrm{~mm}$ on the iris of the cavity, is 180 hours for the bright bath whereas it increases to 
TABLE VII. Current density at the critical points of the cavity, for an average current density of $160 \mathrm{~A} \cdot \mathrm{m}^{-2}$.

\begin{tabular}{lcc}
\hline \hline Current density $\left(\mathrm{A} \cdot \mathrm{m}^{-2}\right)$ & Iris & Equator \\
\hline Direct plated (complex bath) & $88 \pm 5$ & $202 \pm 2$ \\
Pulse plated (no additives) & $52 \pm 6$ & $240 \pm 2$ \\
\hline \hline
\end{tabular}

300 hours for the additive-free bath. In general, due to the geometry of the mandrel, the maximum and minimum current density areas are observed on the equator and iris, respectively. In Table VII, for the bright bath, the current density at the iris is $88 \mathrm{~A} \cdot \mathrm{m}^{-2}$ in contrast with the additive-free bath which exhibits $52 \mathrm{~A} \cdot \mathrm{m}^{-2}$. The current density is directly proportional to the local plated thickness.

Copper plated cavities were produced by increasing the plating time of the assembly to 300 hours. The thickness at the iris and the equator was $2.1 \pm 0.1$ and $6.7 \pm 0.2 \mathrm{~mm}$, respectively. The cavity was vacuum tight and robust on all the $\mathrm{Nb}$ thin film deposition steps (surface preparation, high pressure water rinsing and $\mathrm{Nb}$ coating). Further studies are being developed in order to decrease the plating time by optimizing the current density profile on the cavity. A solution which is being investigated is the addition of a mask on the equator and secondary anode rings close to the iris. Preliminary simulation results show that an optimized geometry of anode and masking highly improves the copper layer thickness uniformity along the cavity.

\section{CONCLUSION}

Electroformed cavities are a viable solution for the production of seamless SRF substrates. Electroformed copper has similar or better mechanical and cryogenic properties than OFE copper and the surface state of the inner copper layer is driven by the surface finishing of the aluminum mandrel.

The electroformed cavities were successfully assembled and were leak tight. The aluminum mandrel was stiff during all of the steps of the process and easily removed by chemical etching. The mandrel dissolution did not modify the inner copper surface of the cavity. The weakest point of the process was the nonuniform thickness distribution along the cavity. COMSOL simulation results agreed with experimental values and helped to predict the total plating time to achieve a thickness of $2 \mathrm{~mm}$ at the iris.

Both electroforming processes have to be explored in the same extent. The pulse plated copper is more promising regarding RRR and conductivity values than the DC electroformed copper, which is better in thickness homogeneity and mechanical strength. The question arises whether a very high thermal conductivity will increase the cavity performance. The effect of copper conductivity on $\mathrm{Nb}$ thin film performance has not been fully assessed yet and will be subject to study in the next steps of the research. In addition, heat treatments could be performed on the cavity prior to the coating to purify the copper. Despite of the possible grain recrystallization upon thermal treatment, the mechanical robustness of the assembly is expected to comply with the required mechanical strength specification.

Furthermore, the surface finishing state of the mandrel can be precisely controlled. The effect of the copper inner surface state in the later $\mathrm{Nb}$ coating can be studied by using different mandrels with increasing roughness. This could lead to a precise study of the influence of the roughness on the performance, which is of high interest for SRF applications.

\section{ACKNOWLEDGMENTS}

This research is supported by the knowledge transfer fund at CERN. The authors would like to thank A. F. Blaser for the microstructure observations. The research leading to this document is part of CERN's Future Circular Collider study.

[1] H. Padamsee, Supercond. Sci. Technol. 30, 053003 (2017).

[2] A.-M. Valente-Feliciano, Supercond. Sci. Technol. 29, 113002 (2016).

[3] C.-Z. Antoine, in Proceedings of the CAS-CERN Accelerator School: Superconductivity for Accelerators, Erice, Italy, 2013 (CERN, Geneva, 2014), http://cds.cern.ch/ record/1507630.

[4] A. Sublet, S. Aull, B. Bartova, S. Calatroni, T. Richard, G. Rosaz, M. Taborelli, M. Therasse, W. V. Delsolaro, and P. Zhang, in Proceedings of the 17th International Conference on RF Superconductivity (2015).

[5] S. Calatroni, Physica (Amsterdam) 441C, 95 (2006).

[6] S. Calatroni, A. Miyazaki, G. Rosaz, A. Sublet, W. V. Delsolaro, R. Vaglio, and V. Palmieri, Phys. Rev. Accel. Beams 19, 092002 (2016).

[7] A. Miyazaki and W. V. Delsolaro, Phys. Rev. Accel. Beams 22, 073101 (2019).

[8] V. Palmieri and R. Vaglio, Supercond. Sci. Technol. 29, 015004 (2016).

[9] H. Padamsee, RF Superconductivity: Science, Technology, and Applications (Wiley, New York, 2009).

[10] V. Palmieri, in MATEC Web of Conferences (2015), Vol. 21, p. 04015, https://doi.org/10.1051/matecconf/ 20152104015.

[11] J. Kirchgessner, in Proceedings of the 3rd Workshop on RF Superconductivity (ANL, Argonne, 1987).

[12] C. Hauviller, in 13th IEEE Particle Accelerator Conference, Chicago, IL (IEEE, New York, NY, 1989), pp. 485-487.

[13] Y. Aue-U-Lan, G. Ngaile, and T. Altan, J. Mater. Process. Technol. 146, 137 (2004).

[14] T. Sokolowski, K. Gerke, M. Ahmetoglu, and T. Altan, J. Mater. Process. Technol. 98, 34 (2000).

[15] W. Singer, X. Singer, I. Jelezov, and P. Kneisel, Phys. Rev. ST Accel. Beams 18, 022001 (2015).

[16] O. Azzolini, G. Keppel, and C. Pira, in Proceedings of the 19th International Conference on RF Superconductivity 
(JACoW Publishing, Geneva, 2019), https://accelconf.web .cern.ch/srf2019/.

[17] J. W. Dini, Thin Solid Films 95, 123 (1982).

[18] C. Benvenuti, V. G. Palmieri, and R. Vaglio, in the 4th Topical Symposium on Superconductivity and Superconducting Materials Technologies, Florence, Italy (Techna, Faenza, 1996).

[19] L. L. Amador, P. Chiggiato, L. Ferreira, V. Nistor, A. Perez Fontenla, M. Taborelli, W. Vollenberg, M.-L. Doche, and J.-Y. Hihn, J. Vac. Sci. Technol. A 36 (2018).

[20] L. L. Amador, Production of ultrahigh-vacuum chambers with integrated getter thin-film coatings by electroforming, Ph.D. thesis, Université Bourgogne Franche-Comte, 2019.

[21] Report No. ASTM-E1876, Standard test methods for dynamic Young's modulus, shear modulus and Poisson's ratio by impulse excitation method, ASTM International Technical Report, 2009.

[22] C. A. Cooper, A. Wu, P. Bauer, and C. Antoine, IEEE Trans. Appl. Supercond. 19, 1399 (2009).

[23] T. Koettig, W. Maciocha, S. Bermudez, J. Rysti, S. Tavares, F. Cacherat, and J. Bremer, IOP Conf. Ser. Mater. Sci. Eng. 171, 012103 (2017).

[24] A. J. Bard and L. R. Faulkner, Electrochemical Methods, Fundamental and Applications (John Wiley \& Sons, New York, 1980).

[25] Report No. ASTM-E112, Standard test methods for determining average grain size, ASTM International Technical Report, 2013.

[26] N. Hansen, Scr. Mater. 51, 801 (2004).
[27] M. Schwartz, Handbook of Deposition Technologies for Films and Coatings-Science (William Andrew Publishing, London, Great Britain, 1994), Chap. 10, p. 506.

[28] W. Singer, A. Ermakov, and X. Singer, TTC-report, 2010.

[29] E. Cantergiani, S. Atieh, F. Léaux, A. T. P. Fontenla, S. Prunet, L. Dufay-Chanat, T. Koettig, F. Bertinelli, O. Capatina, G. Favre, F. Gerigk, A. C. Jeanson, J. Fuzeau, G. Avrillaud, D. Alleman, J. Bonafe, and P. Marty, Phys. Rev. Accel. Beams 19, 114703 (2016).

[30] Report No. ASTM-B170, Standard specification for oxygen-free electrolytic copper-refinery shapes, ASTM Technical Report, 2015.

[31] H. S. Kim, M. D. Sumption, M. A. Susner, H. Lim, and E. W. Collings, Mater. Sci. Eng. A 654, 13 (2016).

[32] F. R. Fickett, IEEE Trans. Mag. Mag. 19, 228 (1983), https://ieeexplore.ieee.org/abstract/document/1062352.

[33] J. G. Hust and A. B. Lankford, Thermal conductivity of aluminum, copper iron and tungsten for temperatures from $1 \mathrm{~K}$ to the melting point NBSIR 84-3007, National Bureau of Standards Technical Report, 1984.

[34] T. R. Bieler, N. T. Wright, F. Pourboghrat, C. Compton, K. T. Hartwig, D. Baars, A. Zamiri, S. Chandrasekaran, P. Darbandi, H. Jiang, E. Skoug, S. Balachandran, G. E. Ice, and W. Liu, Phys. Rev. ST Accel. Beams 13, 031002 (2010).

[35] C.-W. Liu, J.-C. Tsao, M.-S. Tsai, and Y.-L. Wang, J. Vac. Sci. Technol. A 22, 2315 (2004).

[36] C.-W. Liu, Y.-L. Wang, M.-S. Tsai, H.-P. Feng, S.-C. Chang, and G.-J. Hwang, J. Vac. Sci. Technol. A 23, 658 (2005). 